\title{
Variable Use of African American English Across Two Language Sampling Contexts
}

\author{
Julie A. Washington \\ Holly K. Craig \\ Amy J. Kushmaul \\ University of Michigan
}

\begin{abstract}
This investigation compares the impact of two language sampling elicitation contexts, free play and picture description, on variability in the use of African American English (AAE). Subjects were 65 normally developing African American 4;4- to 6;3-year-old boys and girls from lower socioeconomic status homes. Comparisons of AAE production in the first $50 \mathrm{C}$ units revealed significant differences by context. Picture descriptions elicited more AAE usage overall, a larger set of AAE types, and took less time. Gender differences in the use of AAE tokens were also apparent, with the boys using significantly more tokens than girls in the free play context. The use of AAE types and tokens was comparable for boys and girls in the picture description context. The advantages of language sampling with pictures to determine dialect usage is discussed.
\end{abstract}

KEY WORDS: African American English, children, language, contextual variation, African Americans 
Conversational language sampling has long been considered the centerpiece of any assessment of children's language performance (Bloom \& Lahey, 1978; Gallagher, 1983; McCarthy, 1930; Miller, 1981; Miller, Freiberg, Rolland, \& Reeves, 1992; Stockman, 1997). The recorded language produced by a child during an unstructured free play interaction with an adult examiner or a peer is transcribed and analyzed for patterns of conversational language use. The lack of structure imposed on this interaction by the clinician or researcher is believed to provide an optimal context for collection of a language sample that is more representative of the child's linguistic competence than highly structured language sampling contexts such as standardized testing or elicited imitation (Crystal, Fletcher, \& Garman, 1976; Prutting, Gallagher, \& Mulac, 1975; Miller, 1991).

Recent investigations of language sampling have focused on the shortcomings of these unstructured interactions for obtaining samples of a variety of language structures and for making comparisons between individuals or groups of children (Abbeduto et al., 1995; Dollaghan, Campbell, \& Tomlin, 1990; Evans \& Craig, 1992; Wetherby \& Rodriguez, 1992). The inherent variability that characterizes language expression is influenced by situational factors, including the nature of the topics discussed and the familiarity of the interactants (Bloom \& Lahey, 1978; Miller, 1981; Olswang \& Carpenter, 1978). Conversational language sampling in free play is particularly susceptible to the influences of these situational factors, affecting replication of experimental findings (Dollaghan, et al., 1990; Wetherby \& Rodriguez, 1992). In addition, the time-intensive nature of free play sampling, transcription, and analysis are frequently presented as shortcomings of this language sampling method (Dollaghan, et al., 1990; Evans \& Craig, 1992; Miller, 1991; Wetherby \& Rodriguez, 1992).

It is possible to collect samples of language from young children in a structured interaction without sacrificing the reliability and ecological validity of the results obtained. Evans and Craig (1992) compared the language produced by their 8- and 9-year-old subjects with specific language impairment (SLI) in a free play language sampling context and in a more structured interview context. The interview context was a valid and reliable context for eliciting spontaneous language from these older elementary school-aged children. Most language behaviors occurred significantly more often in the interview than in the free play context. Dollaghan, Campbell, and Tomlin (1990) examined the use of video narration as a supplemental language sampling context. They found that by keeping constant the number and complexity of events coded, video narration reduced the variability of language structures produced when compared to free play, providing a more complete picture of the child's linguistic competence when combined with results from a free play language sample. Wetherby and Rodriguez (1992) reported similar results when they examined the use of requests and comments produced by normally developing prelinguistic children during a structured versus unstructured language sampling context. Their subjects produced significantly more requests in the structured context compared to the unstructured free play context.

These investigations of variability in language use in structured and unstructured contexts focused upon children with normally developing or impaired language, all of whom were speakers of Standard American English (SAE). There is a paucity of research available that examines the impact of context on the language produced by children who use nonstandard dialects. Those investigations that do exist have focused primarily on variations in dialect use based on race of the examiner (Agerton \& Moran, 1995; Seymour, Ashton, \& Wheeler, 1986; Terrell, Terrell, \& Golin, 1977). The purpose of this investigation was to examine the use of AAE, a major nonstandard dialect, by young children in an unstructured free play conversational context and in a semistructured picture description context.

The use of AAE varies widely across children and is affected differentially by social status variables such as SES and gender. In our earlier work (Washington \& Craig, 1994), we defined and gave examples of 16 different AAE forms apparent in the discourse of low-income African American preschoolers. Considerable variability of form production was found across this relatively homogenous group of subjects. A hierarchical cluster analysis revealed the presence of 3 distinct groups of dialect users, labeled low, moderate, and high AAE users. The children who were the heavy dialect users did not simply use one form over and over again. Rather, the children who used more tokens in their discourse also used a greater number of different AAE forms. Examination of dialect use in children from differing SES backgrounds revealed variation based upon this important social status variable as well (Washington \& Craig, 1998). Children from low-income backgrounds used significantly more AAE forms than their middle-income peers. Further, examination of dialect use by gender revealed that African American boys used significantly more AAE forms than girls (Washington \& Craig, 1998).

We collected our data (Washington \& Craig, 1994, 1998) during free play dyadic interactions with an adult examiner. It would be advantageous to identify alternative contexts for eliciting AAE that capture the variability in AAE use, but take less time and are more easily replicated. Evans and Craig (1992) found that interviews, which ask more probing questions, potentially limit the number of topics under discussion, and represent a more moderate level of structure, were useful with 
older SAE-speaking children. Picture description was selected as a moderately structured language sampling context for the purposes of this investigation. For younger children, picture description is a frequent context with good ecological validity to preschool and early elementary classroom activities. It presents more question prompts by the examiner but meets the requirements for a spontaneous sample because the child's specific linguistic expectations for responding are not prescribed.

In order to examine potential AAE variability by context the following questions were posed:

1. When corpus sizes are equivalent, are there differences in the number of occurrences of AAE tokens in free play and picture description contexts?

2. Are there differences in the number of AAE types produced in free play and picture description contexts?

3. Are there differences in the amounts of time required to elicit these frequencies of $\mathrm{AAE}$ forms across these two contexts?

4. Are there differences in the frequencies of $A A E$ forms produced by boys and girls in free play and picture description contexts?

\section{Method \\ Subjects}

The subjects were $654 ; 4$ - to 6;3-year-old African American boys $(N=32)$ and girls $(N=33)$ from lowersocioeconomic status (LSES) homes in the Metropolitan Detroit area. Thirty of the 65 subjects were part of the Washington and Craig (1994) study that examined free play only (both free play and picture description language samples were obtained). Socioeconomic status was determined from the demographic characteristics of the children's communities and their participation in a school-based program designed for children growing up in poverty. The younger children were enrolled in one of Metropolitan Detroit's state-funded preschool programs for children at-risk for academic failure, where a number of medical and social status variables comprised the at-risk criteria. All of the current subjects were considered at-risk by virtue of annual family incomes below the poverty line and not by medical factors. The older children were kindergartners and were eligible for the federally-funded free and reduced-price lunch program available to low-income families.

All of the subjects were apparently normally developing according to teacher and parent judgments, and none were enrolled in special education services of any type. Each child passed a bilateral hearing screening at $25 \mathrm{~dB}$ for 500,1000 , and $4000 \mathrm{~Hz}$ (ANSI, 1978) prior to data collection.

\section{Data Collection}

Language samples were collected during adult-child discourse with an African American female examiner who used AAE forms when interacting with the children. The examiner was one of a team of six African American researchers with extensive experience testing children. The child and the examiner each wore a microphone and the samples were audiorecorded using a microphone mixer. The order of elicitation of the free play and picture description language samples was randomized to avoid possible order effects.

Free play was approximately $20 \mathrm{~min}$ in duration. Each child was allowed to select one of three available action toy sets for play during this part of the data collection to maximize potential interest and to standardize interest levels in the play materials across subjects. The toy sets included: Barbie and Ken dolls with a Burger King play set, action figures and props, and the Fisher-Price school. The examiner was instructed to follow the child's lead in the interaction, to engage the child in conversation about the toys and activities, and to formulate comments as well as questions throughout the interaction.

During the picture description task each child was presented with a set of 10 action pictures, which were randomly ordered. The pictures were numbers $5,7,11$, $14,15,22,24,25,28$, and 30 from the Bracken Concept Development Program (Bracken, 1986). These particular pictures were selected because they depicted interesting activities involving males and females, children and adults who were racially diverse. The examiner structured the interaction by instructing the child to "tell me about this picture." If a child simply named objects, the examiner followed up with "tell me what's happening in the picture." Examiners provided positive reinforcement of the child's utterances and formulated requests for clarification as needed. The duration of the picture description task varied, depending upon how much time the child spent describing each picture.

\section{Scoring}

The language samples were transcribed orthographically using the CHAT conventions of the Children's Data Exchange System (CHILDES; MacWhinney, 1994). Instead of utterances, however, the transcripts were segmented into Communication Units (C units), using the scoring criteria of Loban (1976). The first 50 intelligible $\mathrm{C}$ units in each context were identified and scored for the occurrence of one or more types of AAE, using Washington and Craig's (1994) definitions. The AAE scoring categories and examples of each are presented in Appendix A. The 50-C-unit corpus was selected because it is sufficiently large for data reduction and is readily 
obtainable in a 15 to 20 min sampling period from children in this age range. Time from the beginning of each transcript, defined as the initiation of the first child utterance to the end of the fiftieth $\mathrm{C}$ unit, was determined for each free play and picture description sample using a stop watch.

Even though the same AAE features that were scored in Washington and Craig (1994) were used in this study, a different measure was used to explore dialect use in the current investigation. In our 1994 paper the percentage frequencies of utterances containing at least one AAE form were scored. In other work we have found that average $\mathrm{C}$ unit length calculated in words or morphemes increased systematically across the ages of the children in the present investigation (Craig, Washington, \& Thompson-Porter, in press). In this investigation, children's average $\mathrm{C}$ unit length in words was greater in picture descriptions ( $M=4.10 ; S D=0.49$ ) than free play $(M=3.43 ; S D=0.62),[t(64)=5.08 ; p<.0001]$. For each child, the number of AAE tokens was divided by the number of words in the sample. Total number of words rather than the number of utterances was used as a denominator to avoid the undue influence of longer utterance lengths.

\section{Reliability}

Transcription agreement was established for each sample. Approximately $10 \%$ of the discourse of each child in both sampling contexts was retranscribed by an independent observer. A point-to-point comparison for morphemes was high both in free play ( $88 \%$ ) and in the picture description context $(89 \%)$ when the number of agreements was divided by the number of agreements plus disagreements. Agreement for $\mathrm{C}$ unit segmentation was also high in both free play $(98 \%)$ and picture description (99\%).

Fifteen of the subjects were randomly identified and their free play and picture description transcripts rescored by an independent observer using the Washington and Craig (1994) taxonomy for types of AAE. Point-to-point comparisons resulted in $98 \%$ agreement for types in free play and $98 \%$ agreement for types in picture descriptions. Agreement for scoring of AAE tokens was also high for free play $(85 \%)$ and for picture descriptions ( $85 \%$ ).

Dialect use of the examiners was also calculated. The number of subjects tested by a specific examiner was determined according to scheduling availability. Three examiners participated in at least five interactions. Five interactions were randomly selected for each of these three examiners, representing approximately $20 \%$ of the total interactions. The frequencies of AAE tokens varied significantly between examiners in both picture description $[F(2,14)=5.28, p<.05]$ and in free play $[F(2,14)=5.26 ; p<.05)$. Post hoc Tukey tests $(p<$ $.05)$ revealed that one of the examiners used significantly more dialect tokens in both contexts than the other two examiners. The next analysis examined the impact of this variability on the dialect use of the children by comparing the frequencies of AAE types and tokens produced by the children to the frequencies of AAE types and tokens used by the adults. Despite a difference between examiners for tokens, no statistically significant differences were apparent for the frequencies of $\mathrm{AAE}$ tokens (picture description: $[F(2,14)=1.39, p>.05]$, free play: $[F(2,14)=95, p>.05]$ ) or AAE types (picture description: $[F(2,14)=2.68, p>.05]$, free play: $[F(2,14)=2.69$, $p>.05]$ ) produced by the children in these samples. Considered together, these findings indicate that the dialect used by the children was not affected in systematic ways by the variations in dialect used by the examiners.

\section{Results}

The procedures yielded a total corpus of $6,500 \mathrm{C}$ units for analysis. The mean frequencies of tokens and types of AAE per $50 \mathrm{C}$ units in each context are presented in Table 1 . AAE forms were produced more frequently $[t(64)$ $=5.22, p<.001]$ in the picture description context $(M=$ 16.8 tokens) than in the free play context $(M=11.3$ tokens). There were also more $[t(64)=4.13, p=.000] \mathrm{AAE}$ types in picture description $(M=4.9)$ compared to free play $(M=3.7)$.

Table 2 shows the percentage of subjects producing each type in each context. The most frequent types of AAE elicited in each context across subjects were the same: zero copula/auxiliary and subject-verb agreement. No other AAE type was produced by even half of the subjects in either context.

To examine the variability of AAE use across subjects, a hierarchical cluster analysis was applied to the data. This analysis revealed differential use of AAE between the two language sampling contexts. Using AAE tokens divided by words as the dependent variable, three distinct groups of AAE users were identified in the picture description context whereas only two groups were

Table 1. Mean frequencies and standard deviations for African American English tokens and types for picture description (PD) and free play (FP) contexts.

\begin{tabular}{cccccc}
\hline \multirow{2}{*}{ Context } & \multicolumn{2}{c}{ Tokens } & & \multicolumn{2}{c}{ Types } \\
\cline { 2 - 3 } \cline { 5 - 6 } & $M$ & $S D$ & & $M$ & $S D$ \\
\hline PD & 16.8 & 8.2 & & 4.9 & 2.0 \\
FP & 11.3 & 6.3 & & 3.7 & 1.4 \\
\hline
\end{tabular}


Table 2. Percentage of subjects ( $N=65)$ producing each type of African American English in picture description (PD) and free play (FP) contexts.

\begin{tabular}{lcc}
\hline \multicolumn{1}{c}{ Types } & FP (\%) & PD (\%) \\
\hline Zero copula/auxiliary & 100 & 96 \\
Subject-verb agreement & 83 & 80 \\
Fitna/sposeta/bouta & 27 & 31 \\
Ain't & 10 & 1 \\
Undifferentiated pronoun case & 21 & 33 \\
Multiple negation & 11 & 24 \\
Zero possessive & 23 & 37 \\
Zero past tense & 11 & 34 \\
Zero "ing" & 13 & 29 \\
Invariant "be" & 11 & 9 \\
Zero "to" & 9 & 11 \\
Zero plural & 9 & 11 \\
Double copula/auxiliary/modal & 7 & 6 \\
Regularized reflexive & 1 & 7 \\
Indefinite article & 3 & 34 \\
Appositive pronoun & 4 & 10 \\
\hline
\end{tabular}

observed in the free play context (see Figure 1). Compared to free play, picture description evidenced more variability and was the only context in which outliers $(N=3)$, very high dialect users, were apparent. The specific values identified for each group of AAE users are provided in Table 3.

The amount of time it took to elicit the $50 \mathrm{C}$ units was compared by context (see Table 4 ). The mean time in seconds was significantly less $[t(64)=10.64, p=.000]$ in the picture description ( $M=261$ seconds) compared to free play ( $M=468$ seconds) contexts.

Visual inspection of the transcripts suggested that the turn structure of the two contexts varied systematically. An example of a picture description is provided in Appendix B, along with a comparable number of child C units from free play (see Appendix C) collected from a female subject $(4 ; 7)$. The adults produced fewer utterances in the picture description context $(M=47 ; S D=$ 22) than during free play interactions ( $M=109 ; S D=$ 45 ), and these differences were significant statistically $[p(64)=12.41, p<.001]($ see Table 4$)$.
Figure 1. Subgroups of AAE users in Free Play and Picture Description.

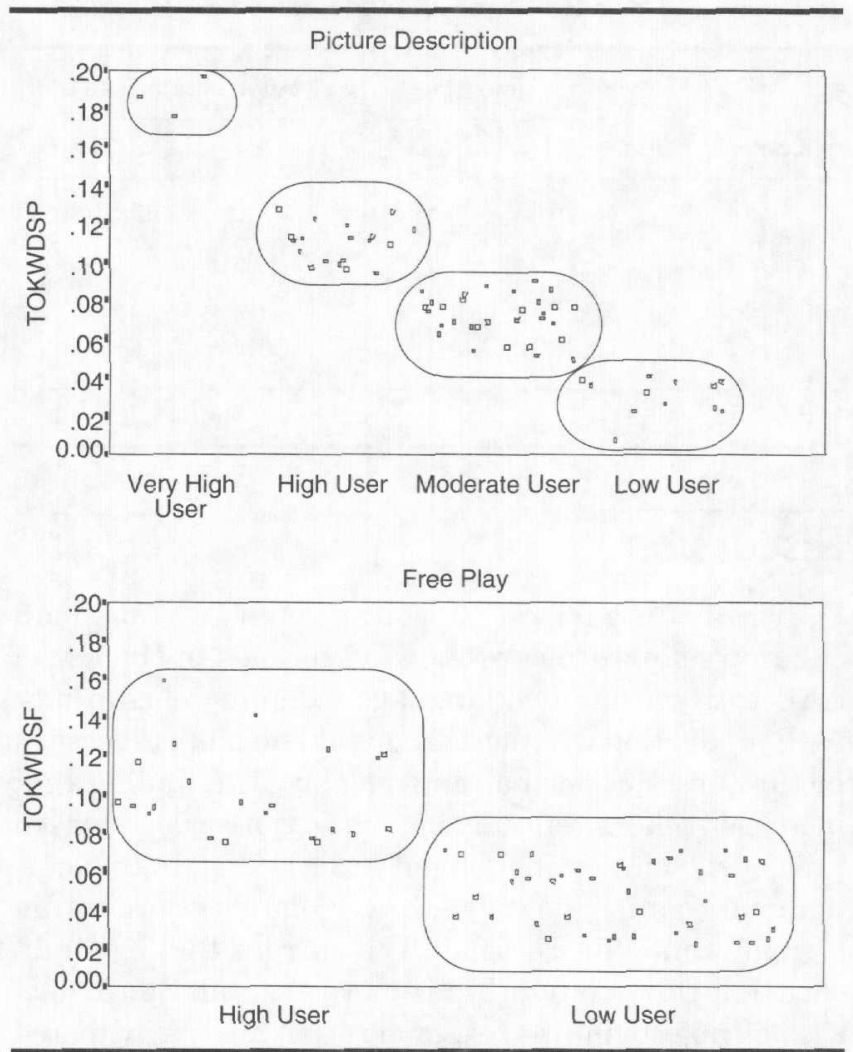

In addition to these differences in the frequency of use of AAE observed by context, a one-way analysis of variance (ANOVA) with a Bonferroni adjustment revealed differences in the use of AAE tokens during free play. The boys produced more AAE tokens ( $M=13.1, S D=7.1$ ) than did the girls $(M=9.2, S D=4.9)$, and these differences were statistically significant $(F(1,64)=5.60, p<.05)$. No differences in the use of AAE types were evident by gender. The observed differences in AAE use by gender did not generalize to the picture description context. The amounts of AAE produced by girls (types: $M=4.6, S D=$ 1.9 ; tokens: $M=16.7, S D=7.6$ ) were comparable to the boys (types: $M=5.2, S D=2.1$; tokens: $M=16.9, S D=8.9$ ) in this context, but these performances were not significant statistically $(F(1,64)=1.34, p>.05)$.

Table 3. The minimum (Min) and maximum (Max) values and standard deviations (SD) of tokens divided by words for the AAE user groups in each context.

\begin{tabular}{|c|c|c|c|c|c|c|c|c|}
\hline \multirow[b]{2}{*}{ Group } & \multicolumn{4}{|c|}{ Free Play } & \multicolumn{4}{|c|}{ Picture Description } \\
\hline & $N$ & Min & Max & $(S D)$ & $N$ & Min & Max & $(S D)$ \\
\hline Very high & - & - & - & - & 3 & .176 & .196 & $(.010)$ \\
\hline High & 22 & .082 & .161 & $(.017)$ & 19 & .094 & .127 & $(.010)$ \\
\hline Moderate & - & - & - & - & 31 & .050 & .091 & $(.011)$ \\
\hline Low & 43 & .024 & .073 & $(.023)$ & 12 & .041 & .031 & $(.010)$ \\
\hline TOTAL & 65 & & & & 65 & & & \\
\hline
\end{tabular}


Table 4. Average sampling time (in seconds) for picture description (PD) and free play (FP), and mean frequencies (M) and standard deviations (SD) for adult utterances produced in each context.

\begin{tabular}{cccccc}
\hline \multirow{2}{*}{ Context } & \multicolumn{2}{c}{ Time $(\mathrm{s})$} & & \multicolumn{2}{c}{ Adult utterances } \\
\cline { 2 - 3 } \cline { 5 - 6 } & $M$ & SD & & $M$ & SD \\
\hline PD & 261 & 59 & & 47.0 & 22.5 \\
FP & 468 & 180 & & 108.7 & 45.3 \\
difference & -207 & $*$ & & -61.7 & $*$ \\
$P$ & .000 & & & .000 & \\
\hline
\end{tabular}

*not applicable

\section{$\overline{\text { Discussion }}$}

This comparison of young African American children's dialect use revealed variations in the use of AAE between the two language sampling elicitations. AAE production was more frequent and more diverse in picture description than in free play. The finding that increased tokens reflected increased types was reported previously by Washington and Craig (1994). In that earlier investigation, however, the correlations were within a single context-free play. The current findings indicate that this relationship is more general. Since 30 of the 65 subjects in this research report also participated in our earlier study, this consistency is not surprising. However, the consistency of this finding in a larger, less variable sample confirms the relationship between the frequency and variety of AAE forms.

Hierarchical cluster analysis revealed the presence of identifiable subgroupings of dialect users in each context, when the dependent variable was total number of $\mathrm{AAE}$ tokens divided by the number of words in the sample. As Figure 1 illustrates, two subgroups were identified in free play, and the subgroupings increased to three in the picture description context. In addition to the three groups in picture description, a small number of outliers who were very high dialect users was also identified in this context. These findings suggest that the use of dialect was more frequent and more variable in picture description than in free play.

The literature on language variability across contexts led us to expect less language variability in the semi-structured context than in the unstructured, free play elicitation context (Dollaghan et al., 1990; Wetherby \& Rodriguez, 1992). Reducing variability is an important goal for language sampling; structured contexts are recommended as one way to accomplish this goal (Dollaghan et al., 1990). Perhaps decreased variability should not be the goal if obtaining a representative sample of dialect use is the desired outcome. There is a continuum of dialect use in the AAE community, from individuals who use no dialect to those who use dialect in nearly one half of utterances produced (Washington \& Craig, 1994). Thus, a language sampling context that yields variable use of dialect forms may be most useful for characterizing dialect in children who use AAE.

The differences in AAE form use by gender in the free play context were consistent with the findings of our other work (Washington \& Craig, 1998) in which we found that our male subjects used significantly more dialect than the females. Wolfram (1986) suggested that differences in the production of nonstandard language forms by gender are most likely the result of differential socialization practices which associate more positive values of masculinity with frequent use of nonstandard dialect forms. The male subjects in this investigation differed significantly from the females in the use of tokens during free play. No gender differences were apparent in the number of different types used. These results were consistent with the findings of Washington and Craig (1998) where we found increased use of tokens, but not types for boys.

The gender differences observed for free play did not generalize to the picture description context. The picture description context represented a moderate level of structure that served to limit the topics of discussion. This may have equalized the production of types and tokens produced by the boys and the girls. Thus, picture description may be a more impartial context for eliciting AAE from young children. This finding suggests that future research should examine gender differences in the language production of African American children in performance contexts other than free play.

Picture description may also present a more ecologically valid picture of the African American child as a classroom dialect user. Picture description more closely resembles the kinds of tasks that might be encountered in an SAE classroom environment than free play. By implication, dialect used in this context may reflect the dialect use observed by the classroom teacher more than that observed by a clinician using free play as the centerpiece of an assessment protocol. As an assessment context, picture descriptions are efficient, an asset for the practicing clinician. More dialect was elicited more quickly, most simply explained by the adult examiners talking more, approximately twice as much as during free play.

Isaacs (1996) observed that a dialect shift occurs between third and fifth grade, such that the use of AAE in the classroom decreases significantly. Accordingly, a task like picture description that is similar to one a child might encounter in the classroom would result in decreased use of AAE. However, the subjects in this investigation were much younger than Isaacs' subjects. The subjects in the current investigation were enrolled in their first year of school and lived in communities where 
African Americans comprised $75 \%$ or more of the total population. Presumably then, these children had experienced little systematic exposure to SAE, unlike third, fifth, and seventh graders who have had repeated exposure to standard classroom English and the SAE of texts and the curriculum in general. Isaacs' subjects were also from middle-income families. In an earlier investigation, we found that the use of dialect varied systematically by SES, with low-income children exhibiting significantly increased use of AAE tokens compared to children from middle-income homes (Washington \& Craig, 1998). However, the outcomes of this study considered together with Isaacs' warrant a caution that perhaps picture description may only be useful for revealing variations in dialect use for children at the time of school entry. It will be important for future research to explore the validity of this context for use with children older than the subjects in this investigation, as well as those who differ by SES. Similarly, future research should provide insight into the transition that occurs between the time of school entry and the subsequent decrease in dialect use (Isaacs, 1996).

Picture descriptions present a turn-taking structure more consistent with young children's monologues (Craig \& Gallagher, 1979; Gallagher \& Craig, 1978), narratives (Scollon \& Scollon, 1981; Stein \& Glenn, 1979; SuttonSmith, 1986; Westby, 1984), and scripts (Johnston, 1982; Nelson, 1981). The finding that an important language form, such as AAE for African American children, varies systematically with discourse genre suggests that it will be important to examine other discourse genres. Systematic differences have also been found in children's use of dialect and narrative style across another important discourse type, the narrative genres (Hester, 1996; Hicks, 1991). Future research may reveal more obvious gender differences in alternative discourse genres, as well as systematic variation in the child's use of $\mathrm{AAE}$ relative to the specific discourse context. The findings of this investigation and of our earlier work (Washington \& Craig, 1994) contribute to this line of inquiry by demonstrating that one characteristic of greater dialect usage by young African American children with normal language skills is a richer variety of forms in one context compared to another.

\section{Acknowledgments}

This investigation was supported by research grant number 1 RO1 DC 02313-01A1 from the National Institute on Deafness and Other Communication Disorders, National Institutes of Health. The authors thank Mollie McRoberts, Maureen Noone, and Connie Thompson-Porter for their contributions to various aspects of the project. Special thanks also to the administrators, teachers, and children in the Pontiac, MI and Oak Park, MI public schools for their support and cooperation.

\section{References}

Abbeduto, L., Benson, G., Short, K., \& Dolish, J. (1995). Effects of sampling context on the expressive language of children and adolescents with mental retardation. Mental Retardation, 33, 279-288.

Agerton, E. P., \& Moran, M. J. (1995). Effects of race and dialect of examiner on language samples elicited from southern African American preschoolers. Journal of Childhood Communication Disorders, 16, 25--30.

American National Standards Institute (ANSI). (1978). Methods for manual pure-tone audiometry. (ANSI S.3.211978). New York: ANSI.

Bacchini, S., Kuiken, F., \& Schoonen, R. (1995). Generalizability of spontaneous speech data: The effect of occasion and place on the speech production of children. First Language, 15, 131-150.

Bates, E. (1976). Language and context: The acquisition of pragmatics. New York: Academic Press.

Bloom, L., \& Lahey, M. (1978). Language development and language disorders. New York: John Wiley and Sons.

Bracken, B. A. (1986). Bracken Concept Development Program. San Antonio, TX: Psychological Corporation.

Craig, H. K., \& Gallagher, T. M. (1979). The structural characteristics of monologues in the speech of normal children: Syntactic nonconversational aspects. Journal of Speech and Hearing Research, 22, 46-62.

Craig, H. K., Washington, J. A., \& Thompson-Porter, C. (1998). Average C-unit lengths in the discourse of African American children from low-income, urban homes. Journal of Speech, Language, and Hearing Research, 41, $433-444$.

Crystal, D., Fletcher, P., \& Garman, M. (1976). The grammatical analysis of language disability: A procedure for assessment and remediation. New York: Elsevier-North Holland Publishing $\mathrm{Co}$.

Dollaghan, C. A., Campbell, T. F., \& Tomlin, R. (1990). Video narration as a language sampling context. Journal of Speech and Hearing Disorders, 55, 582-590.

Evans, J. L., \& Craig, H. K. (1992). Language sample collection and analysis: Interview compared to free play assessment contexts. Journal of Speech and Hearing Research, 35, 343-353.

Fields, T. A., \& Ashmore, L. L. (1980). Effect of elicitation variables on analysis of language samples for normal and language-disordered children. Perceptual and Motor Skills, 50, 911-919.

Gallagher, T. M. (1983). Pre-assessment: A procedure for accommodating language use variability. In T. M. Gallagher $\&$ C. A. Prutting (Eds.), Pragmatic assessment and intervention issues in language (pp. 1-28). San Diego, CA: College-Hill.

Gallagher, T. M., \& Craig, H. K. (1978). Structural characteristics of monologues in the speech of normal children: Semantic and conversational aspects. Journal of Speech and Hearing Research, 21, 103-117.

Hester, E. J. (1996). Narratives of young African American children. In A. Kamhi, K. Pollock, \& J. L. Harris (Eds.), Communication development and disorders in African American children: Research, assessment and intervention (pp. 227-245). Baltimore: Brookes Publishing. 
Hicks, D. (1991). Kinds of narrative: Genre skills among first graders from two communities. In A. McCabe \& C. Peterson (Eds.), Developing narrative structure (pp. 89136). Hillsdale, NJ: Lawrence Erlbaum Associates.

Hoff-Ginsberg, E. (1991). Mother-child conversation in different social classes and communicative settings. Child Development, 62, 782-796.

Isaacs, G. (1996). Persistence of non-standard dialect in school-age children. Journal of Speech and Hearing Research, 39, 434-441.

Johnston, J. (1982), Narratives: A new look at communication problems in older language disordered children. Language, Speech, and Hearing Services in Schools, 13, $144-145$.

Kramer, C., James, S., \& Saxman, J. (1979). A comparison of language samples elicited at home and in the clinic. Journal of Speech and Hearing Disorders, 44, 321-330.

Loban, W. (1976). Language development: Kindergarten through grade twelve. Urbana, IL: University of Illinois Press.

MacWhinney, B. (1994). The CHILDES project: Tools for analyzing talk. (2nd ed.). Hillsdale, NJ: Lawrence Erlbaum.

McCarthy, D. (1930). The language of the preschool child. Institute of Child Welfare Monograph Series 4. Minneapolis, MN: University of Minnesota Press.

Miller, J. F. (1981). Assessing language production in children: Experimental procedures. Baltimore: University Park Press.

Miller, J. F. (1991). Quantifying productive language disorders. In J. Miller (Ed,), Research on child language disorders: A decade of progress (pp. 211-220). Austin, TX: Pro-Ed.

Miller, J. F., Freiberg, C., Rolland, M., \& Reeves, M.A. (1992). Implementing computerized language sample analysis in the public school. Topics in Language Disorders, $12,69-82$.

Nelson, K. E. (1981). Social cognition in a script framework. In L. Ross \& J. Flavell (Eds.), The development of social cognition in children. Cambridge, MA: Cambridge University Press.

Olswang, L., \& Carpenter, R. (1978). Elicitor effects on the language obtained from young language-impaired children. Journal of Speech and Hearing Disorders, 43, $76-88$.

Prutting, C., Gallagher, T. M., \& Mulac, A. (1975). The expressive portion of the NSST compared to a spontaneous language sample. Journal of Speech and Hearing Disorders, 40, 40-48.

Scollon, R., \& Scollon, S. (1981). Narrative, literacy and face in interethnic communication. Norwood, NJ: Ablex.

Scott, C., \& Taylor, A. (1978). A comparison of home and clinic gathered language samples. Journal of Speech and Hearing Disorders, 43, 482-495.
Searle, J. (1969). Speech acts. Cambridge, MA: Harvard University Press.

Seymour, H. N., Ashton, N., \& Wheeler, L. (1986). The effect of race on language elicitation. Language Speech, and Hearing Services in Schools, 17, 146-151.

Stein, N. L., \& Glen, C. G. (1979). An analysis of story comprehension in elementary school children. In R. O. Freedle (Ed.), New directions in discourse processing (pp. 53-120). Norwood, NJ: Ablex.

Stockman, I. J. (1997). The promises and pitfalls of language sample analysis as an assessment tool for linguistic minority children. Language, Speech, and Hearing Services in Schools, 27(4), 355-366.

Sutton-Smith, B. (1986). The development of fictional narrative performances. Topics in Language Disorders, 7 , $1-10$.

SYSTAT. (1992). Evanston, IL: SYSTAT, Inc.

Terrell, F., Terrell, S. L., \& Golin, S. (1977). Language productivity of black and white children in black versus white situations. Language and Speech, 20, 377-383.

Terrell, S. L., \& Terrell, F. (1993). African-American cultures. In D. E. Battle (Ed.), Communication disorders in multicultural populations (pp. 3-37). Boston: Andover Medical Publishers.

Washington, J. A., \& Craig, H. K. (1998). Socioeconomic status and gender influences on children's dialectal variations. Journal of Speech, Language, and Hearing Research, 41, 618-626.

Washington, J. A., \& Craig, H. K. (1994). Dialectal forms during discourse of urban, African-American preschoolers living in poverty. Journal of Speech and Hearing Research, $37,816-823$.

Westby, C. E. (1984). Development of narrative language abilities. In G. P. Wallach \& K. Butler (Eds.), Language disabilities in school age children. Baltimore, MD: Williams \& Wilkens.

Wetherby, A. M., \& Rodriguez, G. P. (1992). Measurement of communicative intentions in normally developing children during structured and unstructured contexts. Journal of Speech and Hearing Research, 35, 130-138.

Wilkinson, L., Heibert, E., \& Rembold, K. (1981). Parents' and peers' communication to toddlers. Journal of Speech and Hearing Research, 24, 383-388.

Wolfram, W. (1986). Nature of communication disorders in culturally and linguistically diverse populations. In O. L. Taylor (Ed.), Language variation in the United States (pp. 73-115). San Diego, CA: College-Hill Press.

$\overline{\text { Received February }}$ 6, 1997

Accepted January 12, 1998

Contact author: Julie A. Washington, Communicative Disoders Clinic, University of Michigan, 1111 East Catherine Street, Ann Arbor, MI 48109-2054. Email: julieaw@umich.edu 